\title{
Resenha: Preservação de Direitos Infantojuvenis: Resenha de um Manual para Educadores
}

\author{
Gian Francisco Fleck ${ }^{1}$ \\ Instituto Brasileiro de Gestão de Negócios - IBGEN, Porto Alegre, RS, Brasil \\ Centro de Estudos Psicológicos sobre Meninos e Meninas de Rua da Universidade Federal \\ do Rio Grande do Sul, Porto Alegre, RS, Brasil
}

Resenha do livro: Poletto, M., Souza, A. P. L., \& Koller, S. H. (Eds.). (2012). Direitos humanos, prevenção à violência contra crianças e adolescentes e mediação de conflitos - Um manual de capacitação para educadores. Porto Alegre, RS: Ideograf.

\section{Book Review: Human rights, prevention of violence against children and teenagers and conflict mediation - A handbook for educators}

Reseña del libro: Derechos humanos, prevención a la violencia contra niños y adolescentes y mediación de conflictos - un manual de capacitación para educadores

É comum afirmar que não se deve julgar um livro por sua capa. Contudo, destaca-se o conteúdo da ilustração que estampa a capa de Direitos Humanos, Prevenção à Violência Contra Crianças e Adolescentes e Mediação de Conflitos Um Manual de Capacitação para Educadores. Embora não permita definir o teor da obra, a imagem aguça a curiosidade e prepara o terreno para o conteúdo do manual.

Há, ao contrário do que se pensa, mais de uma divindade grega para arquetipificação da justiça. Fala-se sempre de Têmis: figura feminina, de olhos vendados, que é justa pois não vê nenhuma das partes. Leva em uma de suas mãos, como símbolo desta imparcialidade, uma balança. Diké, filha de Zeus e Themis, é outra representação da justiça. Esta, ao contrário de sua mãe, julga com os olhos abertos, levando em sua mão direita uma espada - símbolo de força e ação. Na mão esquerda Diké divide com sua mãe o símbolo mater da justiça - a balança. Sem a libra, a arma é pura força e a balança sem a espada é estéril, motivo pelo qual a deusa segura ambos os ícones. Além dos olhos descerrados, é representada com os pés descalços, como quem busca contato com o mundo concreto.

A capa do livro aqui resenhado, mostra uma criança sentada em uma balança. O menino pinta grandes e esbugalhados olhos, usando tinta vermelha, sobre a venda de Têmis. Há um clamor óbvio nesta representação: o desejo de uma transmutação de Têmis para a figura de Diké - o desejo de uma justiça que enxergue e veja a fragilidade da criança em situação de vulnerabilidade social.

Parte das ações do projeto Escola que Protege - Centro de Estudos Psicológicos sobre Meninos e Meninas de Rua/Universidade Federal do Rio Grande do Sul (CEP-Rua/UFRGS), o livro organizado por Michele Poletto, Ana Paula Lazaretti de Souza e Sílvia Koller é uma compilação de textos escritos por pequisadores e trabalhadores da rede de proteção à infância e adolescência das áreas da psicologia, serviço social

Endereço para correspondência: e-mail: giancco@gmail.com 
e epidemiologia. O manual é dividido em quatro seções. Apesar de tratar-se de uma cartilha para consulta à la carte, sugere-se fortemente que os leitores aproveitem o banquete todo. Embora os textos permitam um fácil entendimento, mesmo quando lidos isoladamente, recomenda-se a leitura completa da obra. Promovendo assim um entendimento amplo dos temas abordados, os quais coexistem inevitavelmente indissociáveis no contexto escolar.

$\mathrm{Na}$ seção "Perspectivas Teóricas" apresentam-se os principais conceitos que nortearão as reflexões do manual. "Garantindo Direitos", apesar de contar com muitos aspectos teóricos, aparece separada, pois apresenta recortes da prática em Direitos Humanos. A terceira parte, "Prevenindo a violência", apresenta estratégias de combate às diversas formas de maus-tratos contra crianças e adolescentes e por fim, o texto "Mediação de conflitos no contexto escolar" ganha uma seção à parte, dada a importância da discussão das estratégias restaurativas no território escolar.

\section{O Manual e seu Conteúdo}

O primeiro texto das "Perspectivas Teóricas" apresenta a proposta de Urie Bronfenbrenner, intitulada "Abordagem Bioecológica do Desenvolvimento Humano". A descrição do constructo de contexto é detalhada a ponto de fazer o leitor imaginar-se no centro de um gráfico, desenhando uma rede de sistemas em torno de si. A proposta é pertinente pois evidencia a escola no desenvolvimento da criança, chamando a atenção dos educadores para o relacionamento essencial ao desenvolvimento humano: o processo proximal. Os artigos "Psicologia Positiva" e "Resiliência" convergem com o anterior pois destacam a importância do desenvolvimento das potencialidades do indivíduo e Bronfenbrenner tem na Pessoa um ponto importante de suas proposições.

As perspectivas teóricas apresentadas neste início do manual embasam um entendimento sistêmico do desenvolvimento da criança. Afirmam a certeza do desenvolvimento baseado nas capacidades e a esperança de que mesmo imer- sa em dificuldades - como agressões e extrema pobreza - a criança pode se tornar um cidadão saudável, ciente de suas qualidades e limitações.

Apesar de não estarem na seção de aspectos teóricos, dois textos dedicados à garantia de direitos serão discutidos como tal, pois servem de balisadores para a discussão de outros textos. "Direitos humanos: não são apenas direitos de minorias" e "Direitos da Criança e do Adolescente" são fundamentações históricas destas áreas do direito no Brasil. O primeiro texto é uma ótima introdução ao tema e o segundo destaca apenas os pontos fortes do Estatuto da Criança e do Adolescente (ECA), furtando-se de questionamentos em relação ao estatuto datado do início dos anos 90, que se mostra falho por não conseguir abordar satisfatoriamente novas problemáticas inerentes aos dias atuais como a inclusão digital e a proteção de crianças e adolescentes em meios virtuais.

Como em outras obras nascidas no contexto do Escola que Protege (Baptista da Silva, Lopes, \& Carvalho, 2008 e Faleiros \& Faleiros, 2007), o manual desenvolvido pela equipe do CEP-Rua/ UFRGS tem a preocupação de apresentar formas de encaminhamento diante de violações de direitos. A rede de apoio é apresentada para que o leitor entenda como estes encaminhamentos são feitos de forma articulada. O texto que se detém a explorar as políticas públicas de proteção e serviços prestados é "Rede de Apoio e Proteção: encaminhamentos necessários frente à identificação de violência contra crianças e adolescentes". A mesma abordagem (multidisciplinar) é observada no texto "Direito da Mulher".

A sessão do livro dedicada à prevenção da violência é aberta por um texto -"Violências em diferentes Contextos" - que elenca indicadores que denunciam a presença de maus-tratos. $\mathrm{O}$ texto é estruturado, quase em sua totalidade, em tópicos, como um material de consulta para educadores e profissionais que suspeitam de algum tipo de abuso contra crianças e adolescentes em seus contextos de atuação.

$\mathrm{Na}$ mesma proposta de material de consulta, no texto "Relações de amizade e bullying", fala-se deste que talvez seja o fenômeno mais discutido dentro das escolas na contemporanei- 
dade. Mesmo com toda a discussão, o assunto continua permeado por uma série de equívocos na sua identificação. Este é o tipo de texto que pode auxiliar o diagnóstico de casos autênticos de bullying na escola.

Oferecendo ferramentas para lidar com atritos, o texto "Mediação de conflitos no contexto escolar" versa sobre os conceitos fundamentais desta prática aplicados ao cotidiano da escola. O texto apresenta alternativas de solução de problemas (como o bullying) através dos processos de mediação que colaboram com a disseminação de uma cultura de justiça e paz na escola.

Deleuze (1992) afirma que as palavras precisam ser rachadas para que delas se possam extrair os enunciados. O uso da expressão " $E x$ ploração Sexual de Crianças e Adolescentes" (título de um dos textos) em detrimento de prostituição infantil se dá para esclarecer a ideia de que existe uma relação díspar entre aliciador e vítima, que não se prostitui, mas é prostituída.

O delicado tema da "Violência Sexual contra Crianças e Adolescentes" é abordado de forma direta. A leitura do texto é leve (se for levado em conta o quanto o tema pode ser desagradável ao leitor), acessível a todos os públicos e não $e s-$ petaculariza este tipo de violência. Talvez seja este o texto com maior foco no esclarecimento de distorções, já que o assunto está entremeado de controvérsias disseminadas culturalmente. As definições objetivas e o constante uso de exemplos conduzem à clarificação do tema, possibilitando a introjeção de constructos firmes.

\section{O Manual, suas Limitações e Avanços}

Foram impressas mil cópias do manual. Esta quantidade é inexpressiva diante do número de escolas do país, estimado - segundo dados do Censo Escolar 2011 - em mais de cento e noventa mil (Ploennes, 2013). A solução para enfrentar este problema foi disponibilizar o texto para download. Entretanto, questiona-se a efetividade deste meio de divulgação no Brasil, já que em pesquisa feita em 2010, a Growth from Knowledge (GfK) afirma que o livro digital é desconhecido por $67 \%$ dos brasileiros (Bonatelli,
2010). Ações como a distribuição de marcadores de páginas com o convite para o download e divulgação do manual em redes sociais foram estratégias utilizadas para tentar contornar esta dificuldade.

Não se questiona a utilidade do material para os participantes de encontros presenciais como o Escola que Protege. Entretanto, quando usado sem a presença de um formador, o manual alcançaria seu objetivo? Neste contexto a leitura do material é válida para incentivar o aprofundamento nos temas discutidos ao longo do manual, mas não substituiria a tutoria de um formador.

Outra indagação é em relação a quantidade de tópicos debatidos no livro. Poderia o material ter se aprofundado mais em temas ainda não discutidos se tivesse evitado assuntos abordados em outras obras escritas no âmbito do projeto Escola que Protege? Temas como rede de apoio, enfretamento da violência e direitos da criança e do adolescente já foram estudados tanto por Faleiros e Faleiros (2007) quanto por Baptista da Silva et al. (2008) e o tema Justiça Restaurati$v a$ faz parte do material organizado por Antunes (2010).

Extrapolando os cuidados propostos pelo projeto, a obra tenta estender a proteção da escola também aos seus trabalhadores. O texto "Bem-estar no trabalho e direitos dos trabalhadores em educação", dá atenção especial à saúde mental dos educadores, temática não trabalhada em outras obras do projeto. Pode-se dizer o mesmo do texto sobre os direitos da mulher.

Destacam-se também aspectos do formato do livro. No final de cada texto, apresentam-se sugestões para leitura, listas de filmes sobre a temática, e as lâminas das aulas do Escola que Protege que deram origem àqueles capítulos. Ao lado destas lâminas, apresenta-se espaço para anotações. Estas linhas, abrem espaço para a participação de quem lê, ampliando olhares e instigando fazeres.

Ao comparar o manual com outras obras abrigadas sob a égide do Escola que Protege algumas já citadas anteriormente - o material se diferencia pela abordagem teórica adotada para discussão dos temas inerentes à qualquer configuração do projeto. A abordagem Bioecológica, 
a Psicologia Positiva e os estudos sobre Resiliência conferem ao livro uma visão única dos temas propostos pelos editais do Escola que Protege, dando ao material uma perspectiva ímpar a respeito da promoção e defesa dos direitos da criança e adolescente, bem como da prevenção e combate da violência nas escolas.

\section{Um Convite}

Contrariando ideia de que a rede de apoio à criança e ao adolescente é composta apenas de órgãos formais (escola, Conselho Tutelar, postos de saúde, Promotoria e Juizado da Infância e Juventude...), o livro esclarece que fazem parte dela, também a família e a comunidade. Este tipo de afirmação desacomoda o leitor e o coloca no centro da rede de proteção, na esperança de articulá-lo com os órgãos formais de proteção.

Direitos Humanos, Prevenção à Violência Contra Crianças e Adolescentes e Mediação de Conflitos - Um Manual de Capacitação para Educadores, é resultado do empenho de muitas mãos. É a prova de que a rede de proteção age e de que existe um fazer possível.

Àqueles que não são professores, assistentes sociais, diretores de escola, pais, tios, enfim, aos que acreditam não fazer parte da rede de proteção às crianças e adolescentes pode-se dizer: "Sim. Vocês fazem parte!". Estar atentos às crianças é dever de todos. Por constituírem parte desta rede todos estão convidados a fazer o download do manual em http://www.ceprua. org/livroescolaqueprotege.pdf e por meio de sua leitura descobrir os seus fazeres possíveis.

\section{Referências}

Antunes, H. (Ed.). (2010). Escola que protege: Dimensões de um trabalho em rede. Porto Alegre, RS: Asterisco.
Baptista da Silva, P. V., Lopes, J. E., \& Carvalho, A. (Eds.). (2008). Por uma escola que protege: A educação e o enfrentamento à violência contra crianças e os adolescentes. Ponta Grossa, PR: Editora da Universidade Estadual de Ponta Grossa. Recuperado em http://www.cedeps.com. br/wp-content/uploads/2009/06/LivroEQP.pdf

Bonatelli, C. (2010, 18 ago.). Livro digital é desconhecido por $67 \%$ dos brasileiros. Revista Exame. Recuperado em http://exame.abril.com. br/tecnologia/noticias/livro-digital-desconhecido-67-brasileiros-589158

Deleuze, G. (1992). Conversações. Rio de Janeiro, RJ: Editora 34.

Faleiros, V. P., \& Faleiros, E. S. (2007). Escola que protege: Enfrentando a violência contra crianças e Adolescentes. Brasília, DF: Ministério da Educação, Secretaria de Educação Continuada, Alfabetização e Diversidade. Recuperado em http://portal.mec.gov.br/secad/arquivos/pdf/escqprote_eletronico.pdf

Ploennes, C. (2013, 02 jan.). Brasil fechou 11\% de suas escolas entre 2001 e 2011 aponta censo escolar. Recuperado em http://portal.aprendiz. uol.com.br/arquivo/2013/01/02/brasil-fechou11-de-suas-escolas-entre-2001-e-2011-apontacenso-escolar

Poletto, M., Souza, A. P. L., \& Koller, S. H. (Eds.). (2012). Direitos humanos, prevenção à violência contra crianças e adolescentes e mediação de conflitos - Um manual de capacitação para educadores. Porto Alegre, RS: Ideograf. 